\title{
Critical Appraisal Skills Teaching in UK Dental Schools
}

\author{
Bosun Hong ${ }^{1}$, Emma Plugge ${ }^{1}$
}

1. Cochrane UK, 18 Middle Way, Summertown Pavilion, Oxford, OX2 7LG

\begin{abstract}
Key publications on training in dentistry, including the latest version of the General Dental Council learning outcomes for dentists, recognise the importance of teaching evidence-based practice for dental students. However, dental curriculum designers have considerable flexibility on the scope and approach for teaching evidence-based dentistry (EBD) and there is no readily available information showing how EBD is taught across the dental schools in the United Kingdom (UK). Critical appraisal is one of the key steps of evidence-based decision making and so we investigated through an electronic survey whether and how critical appraisal skills (CAS) are taught and assessed across the UK dental schools. The survey included questions regarding teaching methods, duration and timing of CAS teaching, and assessment methods. Twelve out of the total 16 UK dental schools participated in this survey, giving an institutional response rate of $75 \%$. Whilst all participating 12 UK dental schools reported CAS were taught and assessed in their institution, there were very varied approaches between institutions in every surveyed aspect of CAS education. CAS teaching and assessment strategies should be regularly reviewed in line with the evolving dental curriculum. Regular inter- and intra-institutional review of teaching specifically in evidence-based dentistry including CAS may encourage professional debate regarding facilitation of improved CAS and their integration into clinical practice.
\end{abstract}

Key words: critical appraisal skills, evidence-based dentistry, dental education 


\section{INTRODUCTION}

Evidence-based practice is about making clinical decisions by integrating individual clinical expertise, patient values, and the best available evidence ${ }^{1}$. Recognition of the importance of this concept for dental educators is evident in various publications ${ }^{2,3,4}$. In 2010, an article was published presenting the profile and competences for the European dentist as approved by the General Assembly of the Association for Dental Education in Europe ${ }^{4}$. In one of the seven domains in this profile, 'Knowledge base, information and information literacy', it stated that on graduation, dentists must display the ability to use acquired information in a critical, scientific and effective manner ${ }^{4}$.

The General Dental Council (GDC) published the third edition of 'The first five years'2 in 2008 , relating to their responsibility to regulate the quality of dental education. This stated that dental schools should ensure that dental students should be able to 'evaluate the evidence and critically assess its relevance to treatment planning, advice and treatment provision'2. This document expressed specific learning outcomes of undergraduate dental curriculum at three levels; 'be competent at', 'have knowledge of', and 'be familiar with'. Here 'evidence-based approach' fell into the lowest level, 'be familiar with'2. The word 'critical' was mentioned only once in this document. However, this publication was replaced in 2012 by 'Preparing for Registration'3 which contained a section explaining the fundamental importance of evidence-based dentistry. Indeed increased emphasis on evidence-based dentistry and critical approach can be observed not only by the increased frequency of use of these words but also by the weight placed on them. Application of an evidencebased approach and utilisation of critical thinking skills form one of the seven overarching outcomes that the GDC registrant will be able to demonstrate upon registration ${ }^{3}$. In addition, the ability to critically appraise approaches to dental research and integrate with patient care is recognised as one of the foundations of practice under 'clinical' domain ${ }^{3}$.

Whilst 'Preparing for Registration' provides a direction to incorporate evidence-based dentistry in undergraduate teaching, dental curriculum designers are left with a huge flexibility on the scope and approach for teaching evidence-based dentistry (EBD). Questions have been asked by dental educators; 'Do we simply support undergraduates in learning how to use EBD principles, or should we be going further and encouraging them to become generators of evidence too? And will we put as much emphasis on teaching students how to elicit and understand the values of their patients, as we do on finding the most appropriate trials or systematic reviews? And how will we teach the EBD principles?'5

The classic five steps of evidence-based practice consist of question formulation, literature search, critical appraisal, application of the evidence into clinical practice, and evaluation ${ }^{6}$. We focused on the critical appraisal part of EBD; we aimed to investigate whether and how CAS are taught and assessed across the UK dental schools in order to provide dental educators information on current CAS teaching in UK dental schools for comparison and to encourage debate regarding facilitation of improved CAS education. 


\section{METHODS}

We designed an anonymous electronic survey consisting of seven self-designed questions asking about CAS teaching methods, time spent teaching CAS, and assessment methods. We circulated an e-mail containing the survey web link to the dean, director, or head of the school of all sixteen dental schools in the United Kingdom (UK). The e-mail recipients were invited to either complete this survey, forward the e-mail to, or provide contact details of the most appropriate person(s) in their institution. The survey was open for five weeks, and reminder e-mails were sent during this period. We used Excel to produce descriptive statistics. Following data analysis, we prepared and sent bespoke reports to each responding institution by email.

\section{RESULTS}

Twelve out of the total 16 dental schools in the UK participated in this survey, giving an institutional response rate of $75 \%$.

All respondents reported that their institution provided formal teaching in skills to critically appraise the literature.

\section{CAS teaching methods}

Eleven institutions reported CAS were taught by a combination of methods, and there was one institution where lecture was the only method (Figure 1). The most common combination was 'lecture, workshop, and web-based'. Lecture was the most common $(n=11)$ method to teach CAS, followed by workshop $(n=10)$ and web-based learning $(n=8)$.

One respondent provided details of their optional web-based learning using 'Blackboard' (online space to which a multitude of content can be added). In this institution, the dental public health course lead uploads examples of research papers to Blackboard following relevant lectures. Students then have the option to appraise the papers in their own time. The course lead then uploads his/her version of critical appraisal and notes one month later to Blackboard for students to compare to their own answers.

Another respondent shared a self-designed web-based resource on 'Prezi' (an interactive presentation software); students appraise a randomised controlled trial through this resource before a seminar in which they discuss their own appraisal on another paper.

In six institutions other methods of teaching are used too; these include tutorials (1), journal clubs supported by a senior lecturer (1), special study module (1), production of a critical appraisal piece of work (4,000 words) and a summary Powerpoint presentation to peer group as a formative piece of course work in year four (1), and seminar (2). One respondent provided an example of their seminar methods; students are encouraged to prepare for a seminar by appraising two research papers on the same topic using CAS framework. They then discuss these in small groups of 8-10 students. Staff provide feedback on students' CAS. 


\section{Time spent in learning CAS}

The total number of hours spent by students learning CAS during the Bachelor of Dental Surgery (BDS) programme varied between 11.5 and 30 hours with the average being 22.1 hours. Two respondents stated that it was not possible to quantify this as CAS are integral to many aspects of learning in the BDS programme. Eight respondents provided a breakdown of the hours spent per CAS teaching method as summarised in Table 1.

\section{When are CAS taught during the BDS?}

The number of years in which CAS are taught during the BDS programme varied between one and 'throughout' (Figure 2). Four respondents reported that CAS was taught throughout the BDS programme in their dental school. For example, in one institution, critical thinking teaching begins in the first year. This is linked to the second year 'Microbiology for Dentistry' where skills are enhanced by incorporation of critical thinking and writing skills. In the third, fourth, and fifth years, students are recommended to practise appraising papers using examples uploaded to 'Blackboard', as part of dental public health teaching. In another institution, CAS teaching takes place in plenaries in the first and second years. The main CAS module is in the third year, followed by further activities to consolidate for the remainder of BDS course.

\section{CAS assessment methods}

Eight institutions use a combination of assessment methods for CAS, and four reported the use of one assessment method. The most commonly used CAS assessment method was a written assignment that assessed CAS amongst other skills. Only two institutions used a verbal assignment designed to assess CAS specifically (Figure 3).

\section{Summative assessment}

Eleven out of 12 participating institutions (83.3\%) reported that they conducted a summative assessment in CAS. In one institution, a summative assessment is conducted to specifically assess CAS in the form of a CAS report in the third year. In another institution, there is no stand-alone CAS assessment but the assessment was integrated into other summative assessments throughout the BDS course such as a poster presentation and a summative essay in the first year and written questions on study design in the third and fifth years.

One respondent shared their critical analysis assessment instruction notes and marking scheme. In this assessment, the third year students are required to complete two 2000 word critical writing pieces to a satisfactory level before they can progress to the fourth year. These written works were assessed on six parameters; 'knowledge \& understanding', 'reflection \& analysis' (with the highest weighting), 'relevance to the set task', 'use of source materials', 'structure', and 'use of language'. For each parameter, there were five possible grades; excellent, good, pass, borderline fail, and clear fail.

\section{DISCUSSION}

Our survey results revealed that whilst all participating 12 UK dental schools reported CAS were taught for BDS students, there were very varied approaches between institutions in every surveyed aspect of CAS teaching. However, most 
institutions taught CAS using multiple teaching methods. Given students' different learning needs and styles ${ }^{7,8}$, utilisation of multiple teaching methods is likely to enable teachers to address this diversity of learners by providing them with comfort and tension from familiar and unfamiliar ways of learning ${ }^{7}$.

The art of developing validated evidence-based practice teaching methods has been an ongoing challenge for our medical colleagues, too. The term, evidence-based medicine (EBM), was introduced in $1992^{9}$. Publications such as the 2003 version of Tomorrow's doctors by the General Medical Council ${ }^{10}$ and the Sicily statement ${ }^{11}$ triggered medical educators to shift the emphasis in medical education from conducting research to utilising research to inform clinical practice ${ }^{9}$.

In 2009, Meats et al. ${ }^{12}$ conducted a survey to investigate the state of evidence-based medicine teaching in UK medical schools. This survey highlighted the limited opportunities for medical students to practise and be assessed on CAS, particularly systematic reviews ${ }^{12}$. Whilst their main findings were similar to ours in terms of the greatly varied teaching approaches, they presented some interesting approaches that we did not find in our survey; various forms of 'evidence-based medicine electives', assessing EBM skills in an Objective Structured Clinical Examination, and employing novel methods such as video conferencing with a research team ${ }^{12}$. These methods may well merit further exploration and evaluation in dental education.

A notable finding in our survey was the high number of institutions using web-based teaching methods. The use of technology is increasing in medical education ${ }^{13}$. The two examples of web-based learning provided by the respondents demonstrated different ways in which technology could be utilised for education. In one institution, the teacher's version of critical appraisal is uploaded on the web-based learning environment one month after the exercise becomes available. In the other institution, the students ultimately had the control as to when to reveal the model answers to the critical appraisal.

One of the advantages of web-based learning is its flexibility in regards to time and place, which enables students to work at their own pace and take responsibility for their own learning. Self-directed web-based learning may also serve as a useful strategy to overcome some of the challenges for dental educators such as the limited availability of staff in dental schools to teach CAS and the already crowded BDS curriculum ${ }^{14}$. However, facilitation of learning, of course, relies on student engagement. It has been argued that, if web-based learning is optional, it may not be valued by the learners as much as they would otherwise ${ }^{13}$.

There is no consensus as to the duration or the stage(s) of BDS course at which CAS should be taught to create the habit of evidence-based practice. Some authors have encouraged early introduction of evidence-based medicine into the curricula ${ }^{15,16}$. The responses in our survey again showed considerable variations between institutions in these aspects. Interestingly, CAS tended not to be taught in the final year of the BDS. Whilst this may reflect increased emphasis and commitment on other aspects of the curriculum, it should be noted that the responders might have only chosen the year(s) in which formal or didactic CAS teaching is carried out. It could be that clinical teachers are teaching CAS as a 'hidden curriculum' in the years that the responders have not selected. 
The limitations of didactic teaching or stand-alone courses in helping students integrate EBD into clinical practice have been mentioned in the literature ${ }^{17,18}$. On the other hand, the powerfulness of hidden curriculum in medical education through modelling has been numerously reported ${ }^{19,20,21}$. Concerns have been expressed that evidence-based practice tends to be taught within individual specialities where there is one committed individual ${ }^{14}$. It is important that all dental educators are aware of their potential to become strong motivators of EBD for learners - teachers' values, attitudes, and habits may 'leak' even when unintended.

There is currently a relative lack of validated and practical assessment tools ${ }^{22}$. A recent systematic review identified 104 unique evidence-based practice assessment tools, but only seven of them met the standards for format and validity testing ${ }^{23}$. Our results revealed CAS were assessed by all participating institutions and that many used a variety of assessment methods; written assessments were clearly more widely used than verbal ones. There were institutions assessing CAS only in an integrated manner or both integrated and specific manner, but there was no institution that only used CAS-specific stand-alone assessment methods.

The use of multiple assessment methods is likely to be sensible. It is difficult to conceive that a single assessment method can provide all the data required to make a judgment on a complex topic ${ }^{24}$. Assessment of CAS, especially integration of CAS in clinical practice, can be complex. Assessment of behaviour is arguably more difficult to assess than the facts and concepts due to the subjectivity involved ${ }^{25}$. In addition, there are assessment confounders to be considered, including the student's knowledge base, clinical maturity, faculty guidance, and resource availability within the immediate teaching environment that can alter students' performance at different times ${ }^{24}$.

Assessment can be broadly categorised into formative and summative. Formative assessments are designed to provide learners and teachers with information about competency development during the learning process ${ }^{26}$. Summative assessments are used to document and regulate progression to the next stage of learning. The information gathered from summative assessments usually have high stakes and hence puts pressure on teachers and students, which impacts on various levels from student's motivation, learning experiences of students, and the nature of the assessment ${ }^{26}$. Our finding that the majority of UK dental schools conduct a summative assessment on the ability to critically appraise to determine whether a student qualifies to advance reflects the appreciation of the importance of CAS education for BDS students.

This study investigated an important topic in dental education, and yielded a high response rate. It was unique in that no previous study surveying the current CAS teaching practice across the country could be identified in the literature. Detailed comments from the respondents were particularly valuable in gaining insight into the current CAS teaching. We hope that the bespoke reports sent to each participating institution will provide useful feedback in developing CAS teaching in the future.

We are aware that the scope of this study was limited - its aim was only to capture the current CAS teaching practice, rather than investigating wider EBD or the impact 
on student learning. As stated by Wong et al. ${ }^{27}$, the question to ask would be not just 'what works' but 'what kinds of educational interventions will tend to work, for what kinds of learners, in what kinds of contexts, to what degree, and what explains such patterns?'

One of the broad desirable outcomes of CAS education would be to benefit the key stakeholders of dental education, including the public. One would hope that teaching CAS leads to an increase in evidence-based decision-making behaviour, and ultimately improved patient health and satisfaction. However, the impact of CAS education on these outcomes would be difficult to measure directly ${ }^{28}$. Perhaps reflecting this difficulty, Horsley et al. ${ }^{29}$ found in their Cochrane systematic review that none of the studies addressed patient health or satisfaction outcomes. The authors also noted generally poor quality of studies in this field. Nevertheless, some benefits of teaching CAS were reported in outcomes such as learners' knowledge ${ }^{29}$. Further research could usefully elucidate the important questions raised by Wong et al. ${ }^{27}$ which teaching method facilitates critical appraisal to become a habit, for what kinds of students, in what context, to what degree, and why?

\section{CONCLUSION}

Whilst all participating 12 UK dental schools reported CAS were taught for BDS students, there were varied approaches between institutions in every surveyed aspect of CAS teaching. CAS teaching and assessment strategies should be regularly reviewed in line with the evolving dental curriculum. Regular inter- and intra-institutional review of teaching specifically in EBD including CAS may encourage professional debate regarding facilitation of improved CAS and their integration into clinical practice.

\section{ACKNOWLEDGEMENT}

We thank all respondents and everyone who helped with the circulation of this survey. We are also grateful for support from Cochrane UK.

\section{REFERENCES}

1. Sackett DL, Rosenberg WM, Gray JA, Haynes RB, Richardson WS. Evidence based medicine: what it is and what it isn't. BMJ 1996;312:71-72

2. General Dental Council. The first five years. London, 2008

3. General Dental Council. Preparing for practice: Dental team learning outcomes for registration. London, 2012

4. Cowpe J, Plasschaert A, Harzer W, Vinkka-Puhakka H, Walmsley AD. Profile and competences for the graduating European dentist - update 2009. Eur J Dent Educ 2010;14:193-202

5. Innes N, Hurst D. GDC learning outcomes for the undergraduate dental curriculum. Evid Based Dent 2012;13:2-3

6. Straus SE, Sackett DL. Using research findings in clinical practice. BMJ 1998;317:339-342

7. Vaughn L, Baker R. Teaching in the medical setting: Balancing teaching styles, learning styles and teaching methods. Med Teach 2001;23:610-612

8. Alghasham AA. Effect of students' learning styles on classroom performance in problembased learning. Med Teach 2012;34:S14-S19

9. Evidence-based medicine working group. Evidence-based medicine: a new approach to teaching the practice to medicine. JAMA 1992;268:2420-2425

10. General Medical Council. Tomorrow's doctors. London, 2003 
11. Dawes M, Summerskill W, Glasziou P, Cartabellotta A, Martin J, Hopayian K, Porzsolt F, Burls A, Osborne J; Second international conference of evidence-based health care teachers and developers. Sicily statement on evidence-based practice. BMC Med Educ 2005;5:1

12. Meats E, Heneghan C, Crilly M, Glasziou P. Evidence-based medicine teaching in UK medical schools. Med Teach 2009;31:332-337

13. Yavner SD, Pusic MV, Kalet AL, Song HS, Hopkins MA, Nick MW, Ellaway RH. Twelve tips for improving the effectiveness of web-based multimedia instruction for clinical learners. Med Teach 2014;37:239-244

14. Richards D. Evidence-based dentistry - a challenge for dental education. Evid Based Dent 2006;7:59

15. Srinivasan M, Weiner M, Breitfeld PP, Brahmi F, Dickerson KL, Weiner G. Early introduction of an evidence-based medicine course to preclinical medical students. $J$ Gen Intern Med 2002;17:58-65

16. Forester JP, Cole MS, Thomas PP, McWhorter DL. Introducing critical appraisal of biomedical literature to first-year medical students in histology. J Int Assoc Med Sci Educ 2007;13:21-29

17. Stevenson RG. The educational system's integration of evidence-based principles: what are the obstacles in the dental school environment? J Evid Based Dent Pract 2006;6:5961

18. Straus SE. Evidence-based medicine: how to practice and teach it. $4^{\text {th }}$ ed. Edinburgh: Elsevier Churchill Livingstone, 2011

19. Passi $\mathrm{V}$, Johnson $\mathrm{N}$. The hidden process of positive doctor role modelling. Med Teach 2016;38:700-707

20. Glicken AD, Merenstein GB. Addressing the hidden curriculum: understanding educator professionalism. Med Teach 2007;29:54-7.

21. Gofton W. What we don't know we are teaching: unveiling the hidden curriculum. Clin Orthop Relat Res 2006;449:20-27

22. Flores-Mateo G, Argimon JM. Evidence based practice in postgraduate healthcare education: a systematic review. BMC Health Serv Res 2007;7:119

23. Shaneyfelt T, Baum KD, Bell D, Feldstein D, Houston TK, Kaatz S, Whelan C, Green M. Instruments for evaluating education in evidence-based practice - a systematic review. JAMA 2006; 296:1116-1127

24. Miller RA. Why the standard view is standard - people, not machines, understand patients problems. J med philosophy 1990;15:581-59

25. Marshall TA, Straub-Morarend CL, Guzman-Armstrong S, Handoo N. Evidence-based dentistry: assessment to document progression to proficiency. Eur J Dent Educ 2016; doi: 10.1111/eje.12202. [Epub ahead of print]

26. Harlen W. Teachers' summative practices and assessment for learning - tensions and synergies. Curric J 2005;16:207-223

27. Wong G, Greenhalgh T, Westhorp G, Pawson R. Realist methods in medical education research: What are they and what can they contribute? Med Educ 2011;46:89-96

28. Winning T, Needleman I, Rohlin M, Carrassi A, Chadwick B, Eaton K, Hardwick K, Ivancakova R, Jallaludin RL, Johnsen D, Kim J, Lekkas D, Li D, Onisei D, Pissiotis A, Reynolds P, Tonni I, Vanobbergen J, Vassileva R, Virtanen J, Wesselink P, Wilson N. Evidence-based care and the curriculum. Eur J Dent Educ 2008;12:48-63.

29. Horsley T, Hyde C, Santesso N, Parkes J, Milne R, Stewart R. Teaching critical appraisal skills in healthcare settings. Cochrane Database of Syst Rev 2011;11: CD001270

\section{FIGURE LEGENDS}

Figure 1. CAS teaching methods

Figure 2. Number of years in which CAS are taught during the BDS course

Figure 3. CAS assessment methods

\section{TABLE LEGEND}

Table 1. Number of hours spent per CAS teaching method 